To appear in the Journal of Hydraulic Research

Vol. 00, No. 00, Month 20XX, 1-20

Research paper

\title{
1D morphodynamic modelling using a simplified grain size description
}

BENOÎT CAMENEN (IAHR Member), Researcher, Irstea, HHLY, Hydrology-Hydraulics Research Unit, 5 rue de la Doua, CS 70077, 69626 Villeurbanne cedex, France

Email: benoit.camenen@irstea.fr (author for correspondence)

CLAIRE BÉRAUD, Researcher, Cefas, Lowestoft Laboratory, Pakefield Road, Lowestoft, NR33 0HT, United Kingdom

Email: beraud.claire@gmail.com

JÉRÔME LE COZ (IAHR Member), Researcher, Irstea, HHLY, Hydrology-Hydraulics Research Unit, 5 rue de la Doua, CS 70077, 69626 Villeurbanne cedex, France

Email: jerome.lecoz@irstea.fr@irstea.fr

ANDRÉ PAQUIER (IAHR Member), Researcher, Irstea, HHLY, Hydrology-Hydraulics Research Unit, 5 rue de la Doua, CS 70077, 69626 Villeurbanne cedex, France

Email: andre.paquier@irstea.fr

\section{ABSTRACT}

This paper introduces a 1D numerical code RubarBE for hydraulic and mobile-bed simulations. The code's ability to reproduce the downstream fining of a gravel-sand mixture in response to bed aggradation is tested against laboratory experiments. Unlike in most numerical models, grain size distribution in each sediment layer is not represented using a multi-class model, but using the median diameter $d_{50}$ and a sorting coefficient $\sigma$. The comparison of numerical results with experimental data shows that the adaptation length $L_{a}$, classically used for non-equilibrium sediment transport, is an essential parameter of the model to accurately reproduce the evolution of the deposit front. Empirical laws for adjustments of $d_{50}$ and $\sigma$ are proposed to reproduce sediment sorting through two grain-size related adaptation 9 lengths $\left(L_{d}, L_{\sigma}\right)$. They are scaled by the length of the reach in morphological equilibrium, which is a useful result 10 for the field applications.

Keywords: sediment Aggradation; downstream fining; median grain size; sorting coefficient; 1D numerical model

\section{Introduction}

The numerical simulation of sediment transport and processes along rivers is essential to understand river dynamics and predict river bed evolution. While the bed structure and the sediment grain size distribution should be accurately reproduced in a numerical model, it may induce high computational cost. Modelling strategy consists in finding the best compromise between a detailed representation of driving processes and an acceptable computational cost. Both robustness and parsimony are needed in simulation, since only scarce experimental data are available.

In order to reproduce the bed structure, different layers can be distinguished according to their dynamics. Hirano (1971) introduced a three-layer model:

- the sediment transport layer is the upper layer where sediments are in motion;

- the substrate layer is the bottom layer, which is assumed to be permanently buried with no sediment motion; 
- the active layer is located between the two aforementioned layers and acts as a buffer zone to satisfy sediment continuity between the upper and bottom layers. Sediments within this layer are in constant interaction with the two other layers.

The Hirano (1971) active layer concept is used in many sediment transport models for simulating selective bedload transport (Deigaard, 1980; Mikos̃, 1993; Hoey \& Ferguson, 1994). di Silvio (1992) considers four different layers, dividing the transport layer in two sub-layers for suspension and bedload transport, respectively. Separate equations were also applied in di Silvio (1992) model to quantify horizontal and vertical sediment movement inside a layer or between two layers. Parker (1991) suggested that the active layer thickness $\delta_{A L}$ may be scaled with the grain size of the layer $\left(\delta_{A L} \approx d_{90}\right.$ where $d_{90}$ is the grain diameter at which 90 percent of the distribution in mass lies below). In case of sandy rivers with bedforms, Blom (2008) showed that $\delta_{A L}$ is scaled with the bedform height.

The characterisation of bed layer sediments can be done using different strategies. The common one consists in characterising the grain size distribution by a discrete number of classes. According to Belleudy (2001), the multi-class representation permits to better calculate the transport rate for each class of sediments, including possible interaction between classes. Interactions between classes are generally introduced through a modification of the critical bed shear stress for inception of movement including hiding or exposure coefficients (Egiazaroff, 1955; Parker, 1990; Wu, Wang, \& Jia, 2000; Wilcock \& Crowe, 2003). This representation has been used by many authors to simulate the sediment downstream fining due to selective transport (Parker, 1991; van Niekerk, Vogel, Slingerland, \& Bridge, 1992; Vogel, van Niekerk, Slingerland, \& Bridge, 1992; Langendoen \& Alonso, 2008) or coarsening due to bed degradation (Langendoen \& Alonso, 2008). For this purpose, several authors performed some numerical modelling calibration and validation using the test case presented by Seal, Paola, Parker, Southard, and Wilcock (1997). Wu and Wang (2008) focussed their discussion on the ability of their model to simulate transient flows over movable beds but simulation of grain size evolution was not presented. Cui, Parker, and Paola (1996) and Belleudy (2001) simulated grain size evolution using a multi-class representation but if the reproduction of the aggrading front was in good agreement with experimental results, downstream fining appeared to be sensitive to the grain size description. Fine sediments $(d<2 \mathrm{~mm})$ were excluded from the simulation of Cui et al. (1996). Langendoen and Alonso (2008) presented accurate simulations for both degradation experiments by Ashida and Michiue (1971) and aggradation experiments by Seal et al. (1997) using the channel model CONCEPTS with 14 predefined size classes. In a similar way, Qian, Cao, Pender, Liu, and $\mathrm{Hu}$ (2015) presented a model that yields accurate results for the experiment of Seal et al. (1997) including some interesting qualitative results for the vertical and longitudinal description of the bed. However, in the multi-class representation, sediment transport has to be evaluated for each class of sediment; validation may therefore be difficult, and even often impossible to achieve (Camenen, Holubová, Lukač, Le Coz, \& Paquier, 2011). Indeed, comprehensive data are needed to accurately describe each sediment class and little experimental information exists to properly describe the interaction between classes (Wilcock \& Crowe, 2003). Hoey and Ferguson (1994) showed that a slightly size-selective bedload transport can produce rapid downstream fining, hence models may be strongly sensitive to parameters that are not fully understood such as hiding and exposure parameters. For suspended load, downstream fining may be reproduced through size-dependent variables such as bed concentration or settling velocity. This phenomenon may be predominant compared to bedload transport in case of sandy river (Wright \& Parker, 2005). Blom (2008) stressed the importance of taking into account the variability in bed form geometry in modelling sorting and morphodynamics. It is particularly important for improving the prediction of the adaptation time-scales of the bed surface composition, the vertical sorting profile, and the composition of the bedload transport. However, such models are very sensitive to bed sediment description, and may not be robust enough to simulate real study cases. 
In case of a unimodal grain size distribution such as a log-normal distribution, the distribution can alternatively be represented using two parameters only: the median value $d_{50}$ and the standard deviation of this distribution $\sigma=\sqrt{d_{84} / d_{16}}$ (where $d_{x}$ is the grain diameter at which $x$ percent of the distribution in mass lies below). One difficulty is then to represent hiding or exposure phenomena or more generally selective transport in such a model. The objective of this paper is to evaluate the numerical code RubarBE (El kadi Abderrezzak, Paquier, \& Gay, 2008; Paquier \& El Kadi Abderrezzak, 2008; El kadi Abderrezzak \& Paquier, 2009), which uses the $d_{50}-\sigma$ representation for the grain size distribution and includes specific rules for representing selective transport. The performance of this model is assessed using the test case presented by Seal et al. (1997) for the downstream fining modelling. Eventually, the RubarBE code robustness, capabilities and limits are discussed.

\section{Presentation of the numerical code: RubarBE}

\subsection{Description of the model}

The RubarBE code is a 1D hydraulic mobile-bed numerical code, which solves the Barré de SaintVenant equations (shallow water equations). These equations are solved using a second-order Godunov-type explicit and upwind scheme, which is shock capturing and robust enough to describe transitions between subcritical and supercritical flows (El kadi Abderrezzak et al., 2008; El kadi Abderrezzak \& Paquier, 2009). It should be noted that hydraulic parameters are resolved with a cell-centred scheme (computed in the middle of two cross-sections) while sediment parameters (sediment transport and bed evolution) are resolved with a node-centred scheme (computed at each cross-section) (El kadi Abderrezzak et al., 2008). This particular feature of RubarBE numerical scheme improves its stability especially when bed evolves dramatically. Sediment variables are computed at each time step as well as the riverbed geometry, which is updated using the Exner equation for the sediment continuity:

$$
(1-\phi) \frac{\partial A_{b}}{\partial t}+\frac{\partial Q_{s}}{\partial x}=0
$$

where $\phi$ is the porosity, $A_{b}$ is the cross-sectional area of the bed above a reference datum, $Q_{s}$ is the volumetric sediment transport, $t$ is the time, and $x$ is the longitudinal direction.

An equation describing the non-equilibrium sediment transport $Q_{s}$, i.e. the spatial lag equation (Daubert \& Lebreton, 1967) is introduced to tackle unsteady morphological processes (Bell \& Sutherland, 1983; Armanini \& di Silvio, 1988; Phillips \& Sutherland, 1989; Rahuel, Holly, Chollet, Belleudy, \& Yang, 1989):

$$
\frac{\partial Q_{s}}{\partial x}=\frac{Q_{s *}-Q_{s}}{L_{a}}
$$

where $Q_{s *}$ is the equilibrium sediment transport (or sediment transport capacity) and $L_{a}$ is the nonequilibrium adaptation length, which permits to reproduce spatial lag effects in morphodynamical adjustments of the bed.

The bed is represented using a three-layer model (Figure 1): the transport layer, which includes both bedload and suspended load; the active layer, and the substratum layer, which is divided in a given number of sub-layers. For each layer and sub-layer, the sediment size distribution is represented with the median diameter $d_{50}$ and the sorting coefficient $\sigma=\sqrt{d_{84} / d_{16}}$. Exchanges between layers are calculated according to sediment balance (Balayn, 2001). At each time step $\Delta t$ and for each cell, there is a sediment discharge coming from the upstream cell $Q_{s}^{u p}$ (with a mass $\left.M^{u p}=Q_{s}^{u p} \Delta t\right)$. These sediments interact with the sediments from the bed layer through the active 
layer, which acts as a buffer layer (cf. Figure 1). This results in a sediment discharge toward the downstream cell $Q_{s}^{d n}$ (with a mass $M^{d n}=Q_{s}^{d n} \Delta t$ ). $Q_{s}^{d n}$ will correspond to $Q_{s}^{u p}$ for the next cell.

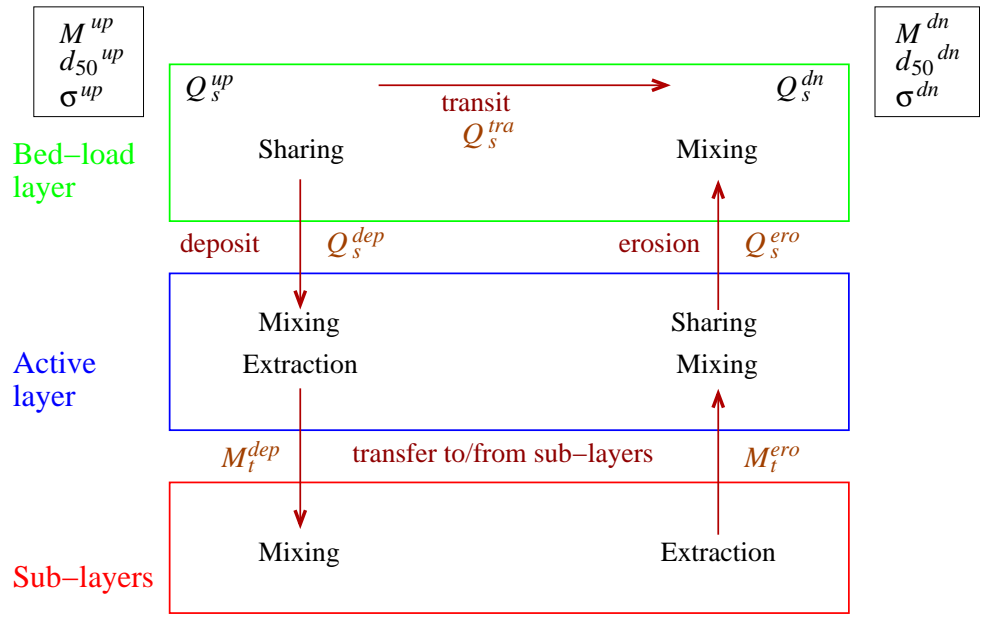

Figure 1 Illustration of the sediment exchanges within a cell of length $\Delta x$ and over a time-step in the RubarBE code.

The sediment discharge transiting directly to the next cell is calculated using the spatial lag equation (Eq. 2 integrated over space without $Q_{s *}$ ):

$$
Q_{s}^{\text {tra }}=Q_{s}^{u p} \exp \left(-\frac{\Delta x}{L_{a}}\right)
$$

where $\Delta x$ is the length of the cell or mesh size. Then, the remaining part of the input sediment $Q_{s}^{d e p}=Q_{s}^{u p}-Q_{s}^{t r a}$ is deposited and mixed with the content of the active layer.

Sediment discharge eroded from the active layer and entrained by the flow is also calculated using the spatial lag equation but based on the equilibrium sediment transport, which is calculated using local hydraulic conditions :

$$
Q_{s}^{e r o}=Q_{s *}\left[1-\exp \left(-\frac{\Delta x}{L_{a}}\right)\right]
$$

Finally, the resulting outward sediment discharge (toward the downstream cell) is $Q_{s}^{d n}=Q_{s}^{\text {tra }}+$ $Q_{s}^{\text {ero }}$ and the sediment mass in the active layer is $M_{A L}(t+\Delta t)=M_{A L}(t)+M^{\text {dep }}-M^{\text {ero }}=$ $M_{A L}(t)+\Delta t\left(Q_{s}^{d e p}-Q_{s}^{e r o}\right)$. The sediment mass in the active layer is defined such as $M_{A L}=$ $M_{A L *}=\rho_{s} Q_{s *} \Delta x / U$ where $U$ is the current velocity. $M^{d e p}$ is first mixed with $M_{A L}$, then, $M^{d e p}$ is extracted from $M_{A L}$ (cf. Figure 1). Depending on the remaining mass in the active layer, there is a direct exchange of mass with the upper bed layer (extraction if $M_{A L}(t+\Delta t)<M_{A L *}$ or mixing if $\left.M_{A L}(t+\Delta t)>M_{A L *}\right)$.

Since the present model using $d_{50}$ cannot reproduce selective transport through a sediment capacity formula or the non-equilibrium adaptation length, grain size evolution is modelled here through sediment exchanges. Sediment exchanges between each layer are reproduced using three main rules, which allow to reproduce effects of selective erosion or deposition (cf. Figure 1):

- mixing law: homogeneous mix of two sediment populations;

- sharing law: sharing of a sediment population into two different sediment populations following an empirical spatial lag equation;

- extraction law: sharing of a sediment population into two sediment populations with identical grain size characteristics as the initial one. 
The mixing law for two samples is calculated using a mass weighted average between the geometric median diameter and standard deviation of the two amounts of sediment for each class (El kadi Abderrezzak \& Paquier, 2009):

$$
\left(\begin{array}{c}
M_{a} \\
d_{50 a} \\
\sigma_{a}
\end{array}\right) \oplus\left(\begin{array}{c}
M_{b} \\
d_{50 b} \\
\sigma_{b}
\end{array}\right)=\left(\begin{array}{rl}
M & =M_{a}+M_{b} \\
d_{50} & =d_{50 a} \frac{M_{a}}{M_{a}+M_{b}} \times d_{50 b} \frac{M_{b}}{M_{a}+M_{b}} \\
\sigma & =\sigma_{a}^{\frac{M_{a}}{M_{a}+M_{b}}} \times \sigma_{b^{\frac{M_{b}}{M_{a}}}}
\end{array}\right)
$$

The sharing law is introduced to separate an initial sediment sample into two sub-samples, the first one, which is finer, is transported by the flow, whereas the second one, which is coarser, settles down. It is based on Eq. 2, which can be written as $\partial d_{x} / \partial x=\partial d_{x} / \partial Q_{s}\left(Q_{s *}-Q_{s}\right) / L_{a}$ where $d_{x}$ is the grain diameter for which $x$ percent of the distribution in mass lies below. Assuming the term on the right-hand side of the equation is a linear function of $d_{x}$, the spatial evolution of both median grain size and standard deviation can be described by an exponential function. The grain size characteristics of the finer class depends on the mass $M_{f}=Q_{s}^{\text {tra }} \Delta t$ or $Q_{s}^{\text {ero }} \Delta t$ taken from the total initial mass $M$, and is given by Balayn (2001):

$$
\left\{\begin{aligned}
d_{50 f} & =d_{50} \times \exp \left[-\frac{\Delta x}{L_{d}} \times \frac{\sigma-1}{\sigma} \times \frac{M-M_{f}}{M}\right] \\
\sigma_{f} & =\sigma \times \exp \left[-\frac{\Delta x}{L_{\sigma}} \times \frac{\sigma-1}{\sigma} \times \frac{M-M_{f}}{M}\right]
\end{aligned}\right.
$$

where $L_{d}$ and $L_{\sigma}$ are the adaptation lengths related to the median diameter evolution and sorting coefficient evolution, respectively. Similarly, the coarser class (mass $M_{c}=M-M_{f}$ ) in the sharing law is given by :

$$
\left\{\begin{aligned}
d_{50 c} & =d_{50} \times \exp \left[\frac{\Delta x}{L_{d}} \times \frac{\sigma-1}{\sigma} \times \frac{M-M_{c}}{M}\right] \\
\sigma_{c} & =\sigma \times \exp \left[\frac{\Delta x}{L_{\sigma}} \times \frac{\sigma-1}{\sigma} \times \frac{M-M_{c}}{M}\right]
\end{aligned}\right.
$$

One should note that a sediment sample that has been shared and mixed again comes back to the same sample. The coefficients $(\sigma-1) / \sigma$ and $\left(M-M_{f}\right) / M$ were introduced to limit sediment evolution in case of a well sorted sediment or limited sediment transport. And if $L_{d}=L_{\sigma}=\infty$, the sharing law reduces to the extraction law: the grain-size characteristics of the two classes are the same.

\subsection{Non-equilibrium adaptation length}

The non-equilibrium adaptation length usually depends on the flow characteristics and sediment size (Armanini \& di Silvio, 1986; Phillips \& Sutherland, 1989). For bedload transport, Phillips and Sutherland (1989) suggested that $L_{a}$ would be directly proportional to the average step length of grains, and eventually proposed:

$$
L_{a}=\alpha_{L, P S}\left(\theta-\theta_{c r}\right) d_{50}
$$

with $\alpha_{L, P S} \approx 5000$. For suspended load, it has been approximated as a function of the depth averaged velocity $U$, water depth $h$ and settling velocity of the sediment $W_{s}$ (Armanini \& di Silvio, 
1986):

$$
L_{a}=\alpha_{L, A S} \frac{U h}{W_{s}}
$$

where the coefficient $\alpha_{L, A S}$ is a decreasing function of the ratio $W_{s} / u_{*}$. Both $Q_{s *}$ and $L_{a}$ are sensitive to the grain size for bedload when $\theta$ is close to $\theta_{c r}$, and for suspended load. As a consequence, for a multi-class model, the use of Eq. 2 enhances the variation of the grain size distribution, which may be difficult to calibrate. Most of these models use a hiding-exposure function that limit these effects (Hoey \& Ferguson, 1994; Wu, Viera, \& Wang, 2004; Langendoen \& Alonso, 2008; Viparelli, Sequeiros, Cantelli, Wilcock, \& Parker, 2010; Stecca, Siviglia, \& Blom, 2014). The use of Eq. 2 for the $d_{50^{-}} \sigma$ parametrisation impacts bed evolution only, not grain size distribution.

Based on their own model results with several degradation and aggradation cases, Wu et al. (2004) adopted the equation $L_{a}=7.3 h$, corresponding to the ripple wave length. As shown by Wu et al. (2004), $L_{a}$ is an important parameter for numerical stability; and the smaller $L_{a}$ values are used, the smaller grid sizes are required, inducing in turn a smaller time step for numerical stability purpose. In natural situation, because of the larger spatial and time scales, large mesh sizes and time steps are usually used limiting the effect of small $L_{a}$ values. It may explain the large values suggested by Rahuel et al. (1989); Belleudy (2000, 2001); El kadi Abderrezzak et al. (2008), especially for $1 \mathrm{D}$ modelling that integrates $2 \mathrm{D}$ and 3D effects. $L_{a}$ may thus be scaled by larger morphological characteristics such as meanders, gravel bar length, etc. and so may be scaled to the width of the river $B$.

\subsection{Grain-size related adaptation lengths}

The sharing law is based on Sternberg (1875), who observed that the characteristic grain size of a river follows an exponential law of the longitudinal distance:

$$
d=d_{0} \exp \left(-\alpha_{d} x\right)
$$

where $x$ is the longitudinal distance and $d_{0}$ is the grain size at $x=0$. Both $L_{d}$ and $L_{\sigma}$ are parameters that drive this grain sorting; they can be scaled with a distance. As a first guess, $L_{d}$ et $L_{\sigma}$ would be taken larger than $L_{a}$ since $L_{a}$ is representative of one step length and may be scaled to the width of the river $B$ for a $1 \mathrm{D}$ model as discussed above. Grain sorting could be observed after many step lengths only and is observed on relatively long distances (from several dozens of metres for a gravel bar to several $\mathrm{km}$ for a river main channel). Morris and Williams (1999) showed that $1 / \alpha_{d}$ is proportional to the length $L$ of the reach in morphodynamical equilibrium (see Figure 2). Since $L_{d} \propto 1 / \alpha_{d}$ based on Eqs. 6 and 7, one can assume that $L_{d} \propto L$, which means that this coefficient should be scaled by the length of the reach in equilibrium. In Figure 2, some additional experimental values that include an estimation of $\alpha_{\sigma}$ were added (Seal et al., 1997; Toro-Escobar, Parker, \& Paola, 2000; Ferguson, Church, \& Weatherly, 2001; Gomez, Rosser, Peacock, Murray Hicks, \& Palmer, 2001; Surian, 2002). It appears that $\alpha_{\sigma} \propto 1 / L$ as well, although some larger uncertainties exist. Apart from the case of Toro-Escobar et al. (2000) with fine sands, one can observe that generally, $1 / \alpha_{d}>1 / \alpha_{\sigma}$. Based on Eqs. 6, 7, and 10, one can first suggest that $L_{\sigma} \propto L$ and $L_{\sigma} \geq L_{d}$. 


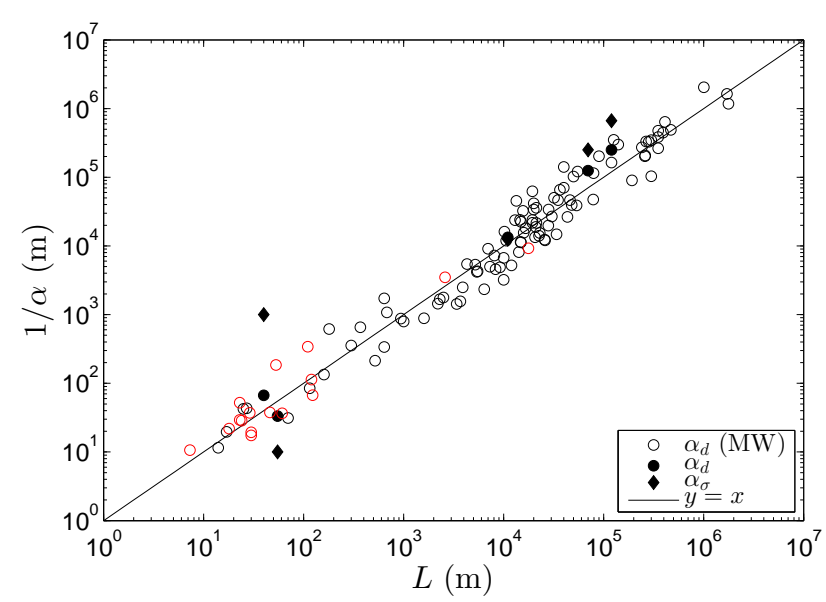

Figure 2 Relationship between coefficients $\alpha_{d}$ and $\alpha_{\sigma}$ and the length $L$ of the reach in equilibrium $\left(\alpha_{d}(\mathrm{MW})\right.$ stands for data given by Morris and Williams (1999), red dots correspond to negative values or coarsening reaches).

\section{Downstream fining experiments}

\subsection{Experimental set up}

The main objective of the experiments performed at St Anthony Falls Laboratory by Seal et al. (1997) was to reproduce the downstream fining of a gravel-sand mixture in response to bed aggradation. The three tests were conducted in a $45 \mathrm{~m}$ long, $0.305 \mathrm{~m}$ wide and $1.2 \mathrm{~m}$ deep flume with an initial bed slope set at $0.20 \%$ (Figure 3 ). The bed and the walls were covered with a smooth PVC membrane. The downstream boundary condition was set thanks to a tailgate $\left(H_{\text {tail }}\right)$ imposing a constant downstream water height $z_{w, \text { tail }}$ for each of the three runs (Seal, Parker, \& Mullenbach, 1995).

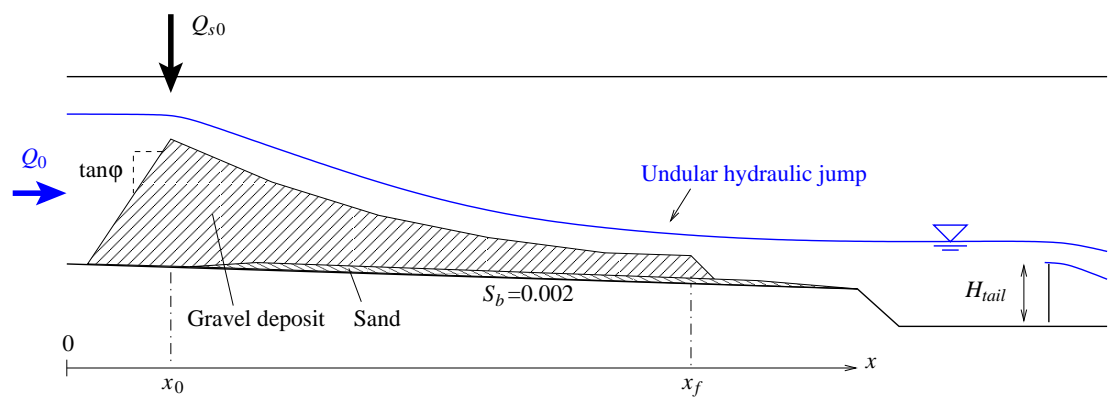

Figure 3 Schematic drawing of the experimental set up of Seal et al. (1997).

\subsection{Description of the downstream fining experiments}

The input mixture, ranging from 64 to $0.125 \mathrm{~mm}$, was a mixing of three sediment samples with mean diameters equal to 22,5 and $0.4 \mathrm{~mm}$, respectively. The final experimental distribution was a poorly sorted sand and gravel mixture. However, since Seal et al. (1995) observed that very fine sediments were flushed away and deposited directly downstream of the channel, and represented approximately $4 \%$ of the total mass, the grain size distribution was truncated in the numerical model at $d=0.15 \mathrm{~mm}$ (Cui et al., 1996; Toro-Escobar, Parker, \& Paola, 1997) and the solid discharge decreased by $4 \%$. Both raw and adjusted grain size distributions for the sediment input are presented in Figure 4 . Eventually, the sediment characteristics used in the model are $d_{50}=7.5 \mathrm{~mm}$ 
and $\sigma=6.0$. The distribution is properly represented by a median diameter $d_{50}$ and a sorting coefficient $\sigma=\sqrt{d_{84} / d_{16}}$ corresponding to a log-normal distribution, although both recalculated $d_{16}$ and $d_{84}$ appear to be overestimated $\left(d_{16^{\prime}}=d_{50} / \sigma=1.3 \mathrm{~mm}, d_{84^{\prime}}=d_{50} \sigma=45 \mathrm{~mm}\right.$ instead of $\left.d_{16}=0.8 \mathrm{~mm}, d_{84}=35 \mathrm{~mm}\right)($ Figure 4$)$.

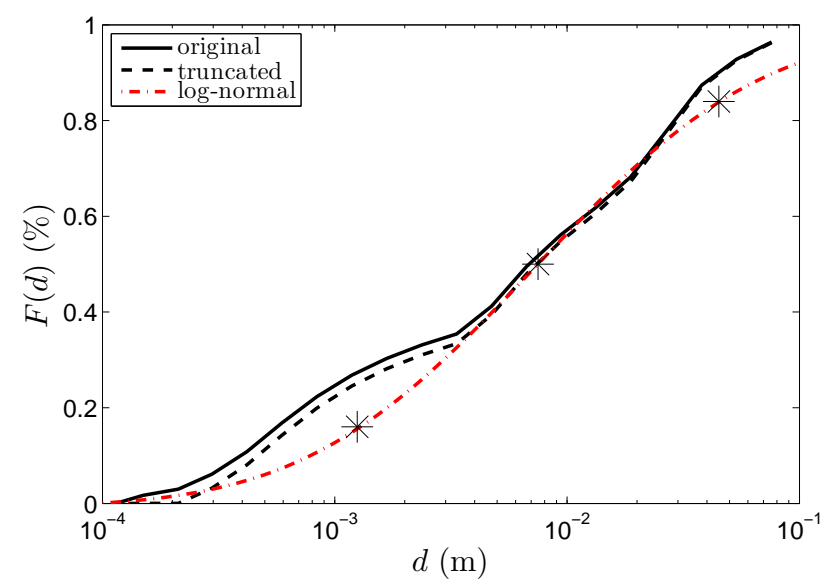

Figure 4 Grain size distribution of the input mixture in Seal et al. (1997) experiments $(F(d)$ : cumulative mass $(\%)$; dash line corresponds to a readjustment of the grain size distribution of the sediment input, crosses to $d_{50}$ and $d_{16^{\prime}}$ and $d_{84^{\prime}}$ obtained from the $d_{50}-\sigma$ representation, and dash-dot line to the corresponding log-normal curve).

In the numerical model like in the experiment description, no sediment is present on the bed at the initial time. In the experiments, the sediment input is injected at the longitudinal distance $x_{0}=1 \mathrm{~m}$. In the numerical model, as the flume starts at the abscissa $x_{0}=1$, the backslope gravel transport at the flume entrance (cf. Figure 3) is not simulated. Nevertheless, according to Seal et al. (1997), only sediment involved in transport is defined as sediment input, making our approximation acceptable.

Sediment input $Q_{s 0}$ was decreased by a factor two from one run to another but the water discharge $Q_{0}$ remained unchanged (Table 1). The downstream fining in this simulation is not only due to selective transport but also due to selective deposition (Paola \& Seal, 1995; Seal et al., 1995; Ferguson \& Wathen, 1998). Toro-Escobar et al. (1997) argued that infiltration may have occurred during the experiment and quantified it using a calibration parameter. As the width to depth ratio was less than 0.2, the bed form effect is neglected (Colombini, Seminara, \& Tubino, 1987), and in principle 1D modelling can reproduce bed evolution.

\begin{tabular}{|c|c|c|c|c|}
\hline Run & $Q_{0}\left(\mathrm{ls}^{-1}\right)$ & $Q_{s 0}\left(\mathrm{kgs}^{-1}\right)$ & $z_{w, \text { tail }}(\mathrm{m})$ & $T_{f}(\mathrm{~h})$ \\
\hline 1 & 49 & 0.1900 & 0.40 & $16 \mathrm{~h} 50 \mathrm{mn}$ \\
\hline 2 & 49 & 0.0950 & 0.45 & $32 \mathrm{~h} 24 \mathrm{mn}$ \\
\hline 3 & 49 & 0.0475 & 0.50 & $65 \mathrm{~h} 00 \mathrm{mn}$ \\
\hline
\end{tabular}

\subsection{Porosity of the deposit}

The porosity of the deposit has been estimated based on the calculation of the cumulated sediment input, reduced by $4 \%$ since the mass of fine sediments found downstream of the channel equalled to $4 \%$ (Seal et al., 1995), and the volume of the deposit $V$. The sediment input rate used hereafter will be $Q_{s 0, a d j}=0.96 \times Q_{s, i n}$. As a consequence, we obtained $\phi=\left(V-Q_{s 0, a d j} / \rho_{s}\right) / V$. One can 
observe in Figure 5 a slight reduction of the porosity with time, at least for run 2 and 3, indicating that infiltration occurred during the experiment as discussed by Toro-Escobar et al. (1997).

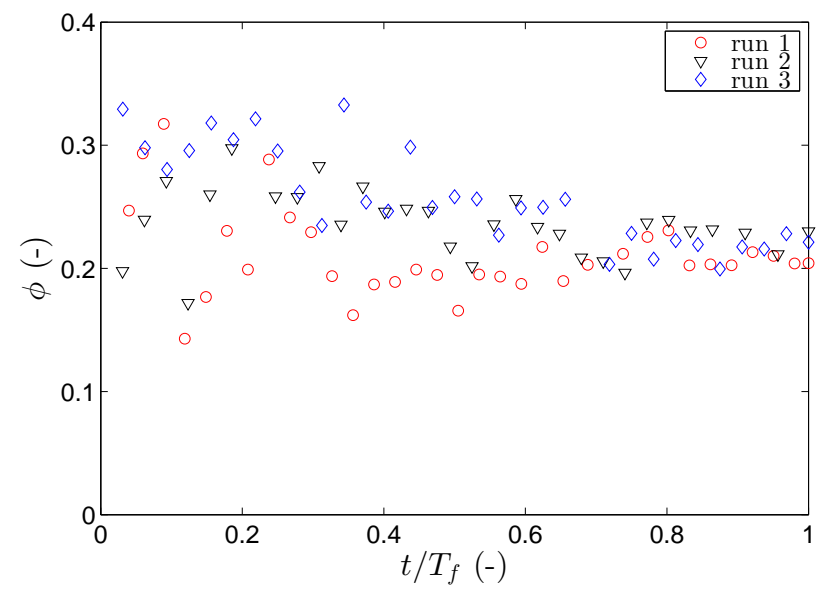

Figure 5 Estimated evolution of the deposit porosity for the three runs based on the cumulated mass introduced and the volume of the deposit.

When having a mixture of sediments of various grain sizes, one can observe some infiltration of the finest class within the pores of the coarsest class leading to a lower overall porosity following this simple linear relationship: $\phi=\phi_{c}-c_{f}\left(1-\phi_{f}\right)$, where $\phi_{c}$ and $\phi_{f}$ are the porosity of the coarse and fine sediments respectively and $c_{f}$ the volume concentration of fine sediments. A minimum is obtained for $c_{f}=\phi_{c}$ and $\phi_{\min }=\phi_{c} \phi_{f}$. Actually, this simple model is valid only if $d_{f} \ll d_{c}$. $\mathrm{Yu}$, Standish, and McLean (1993) suggested a model for the porosity of bimodal mixture taking into account the ratio $r_{d}=d_{f} / d_{c}$ through some empirical relationship. Following Parker and Cui (1998) and Cui and Parker (1998), and assuming the sediment mixture is bimodal (with $35 \%$ of fine sediments, $d_{f} \approx 0.4 \mathrm{~mm}$ and $65 \%$ of coarse sediments, $d_{c} \approx 20 \mathrm{~mm}$ ) with a porosity $\phi=0.4$ for each single class, the $\mathrm{Yu}$ et al. (1993) model gives a theoretical overall porosity of a bimodal mixture with $r_{d} \approx 0.02$ equal to $\phi \approx 0.2$. This is consistent with the estimated final porosity for the deposit for the three runs (Figure 5) assuming the mass of fine sediments found downstream of the channel equal to 4\% (Seal et al., 1995). For our calculations, we used a constant porosity $\phi=0.2$ assuming there is no delay in the mixture equilibrium and so no infiltration during the experiment.

\subsection{Position of the front}

The deposit front $x_{F}$ can be defined either as the position, for which $95 \%$ of the total deposit is located upstream $\left(V_{95 \%}\right)$ or as the position for which the local slope is maximum $\left(S_{F}\right)$. The choice of $95 \%$ of the volume was made in order to avoid effects of uncertainties in the calculation of the volume. It can be observed in Figure 6 that both methods yield similar results for the time-averaged front velocity $C_{F}$ (with the initial time as a reference), i.e. the front velocity decreases from $3 \times 10^{-3}$ to $6 \times 10^{-4} \mathrm{~ms}^{-1}$. On the other hand, these methods differ significantly for the estimation of the instantaneous front velocity (with the previous time step as a reference), although both methods confirm the observation made by Seal et al. (1997) that the front moves irregularly. The first method $\left(V_{95 \%}\right)$ is more sensitive to the overall bed description whereas the second method $\left(S_{F}\right)$ is more sensitive to the exact position of the front, and therefore often yields a zero value. The first method $\left(V_{95 \%}\right)$ will be used hereafter to estimate the front velocity. 


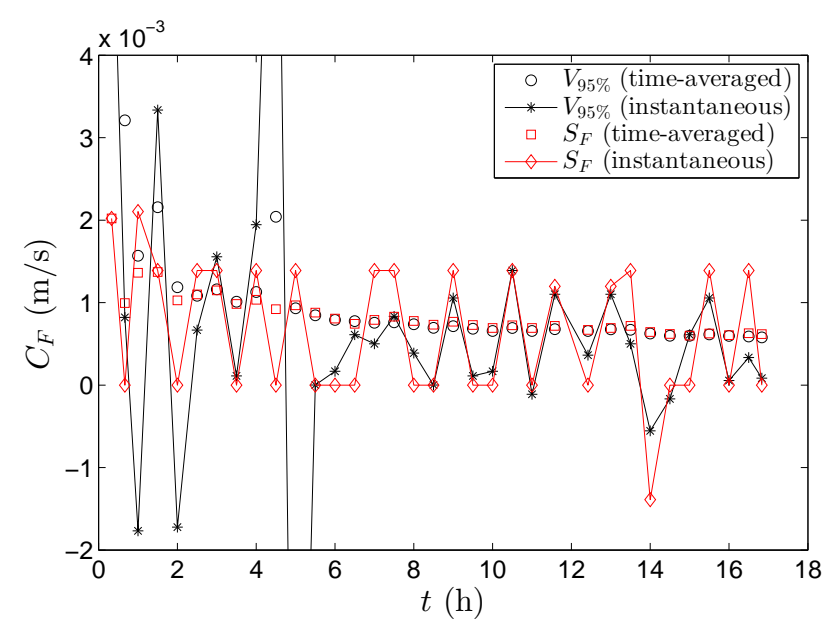

Figure 6 Front velocity estimation for the run 1 as a function of time (front position defined either as the position for which $95 \%$ of the total volume of deposit is located upstream $\left(V_{95 \%}\right)$ or the position for which the local slope is maximum $\left(S_{F}\right)$ ).

\section{Numerical results and discussion}

RubarBE code was run using a relatively loose mesh size $(\Delta x=1 \mathrm{~m})$ to show its robustness. Nevertheless, a discussion on the sensitivity to the mesh size is presented. For all the computations presented here, the bed was represented by a single layer of sediments and a constant water depth downstream. The transport capacity equation from Meyer-Peter and Müller (1948) is used together with the critical bed shear stress calculated according to the Shields diagram. The model results are obviously sensitive to the choice of the transport capacity formula. It is yet not the purpose of this paper to discuss this point (El kadi Abderrezzak \& Paquier, 2011).

\subsection{Bed evolution}

Numerical results of the bed evolution are presented in Figure 7 for the run 1 for four distinct time steps from $T_{f} / 4$ to $T_{f}$ where $T_{f}$ is the final time of the run. The Strickler coefficient was estimated based on the sediment characteristics (Strickler, 1923), i.e. $K_{s} \approx 23 / d_{50}^{1 / 6}=52 \mathrm{~m}^{1 / 3} \mathrm{~s}^{-1}$. Results presented here were obtained using the Meyer-Peter and Müller (1948) bedload formula with no additional fit. A non-equilibrium adaptation length $L_{a}=2 \mathrm{~m}=2 \Delta \mathrm{x} \approx 7 \mathrm{~B}$ yields results in good agreement with experimental data (Figure 7) (Béraud, Le Coz, Camenen, \& Paquier, 2011). It however appears with time that the slope of the deposit is slightly too mild; a stronger tilt would be needed to match the measured deposit elevation at both ends. The small mismatch at both ends may be linked to the choice of the bedload formula and critical bed shear stress (estimated from the Shields curve here).

The Froude number along the flume was calculated for the three runs at the final time-step (cf. Figure 8). Significant uncertainties exist in the estimation of the Froude number since small water depths are difficult to measure. It appeared that supercritical flow conditions always occurred in the first part of the channel especially for the run 1 as large sediment inputs generate large deposits and a sharp decrease in the water depth. For the run 1, on can observe that the Froude number is above 1 all along the deposit and reaches $\mathrm{F} \approx 1.4$ at its upstream part. The RubarBE model reproduces properly the estimation of the Froude number with however a slight underestimation for the run 1 but not as pronounced as with the model by Cui et al. (1996). Their model using a coupled or decoupled scheme underestimates the Froude number for run 1 but yields consistent results. The models used by Wu and Wang (2008); Langendoen and Alonso (2008) were shown to handle both sediment transport and channel evolution under transcritical flow conditions. However, 


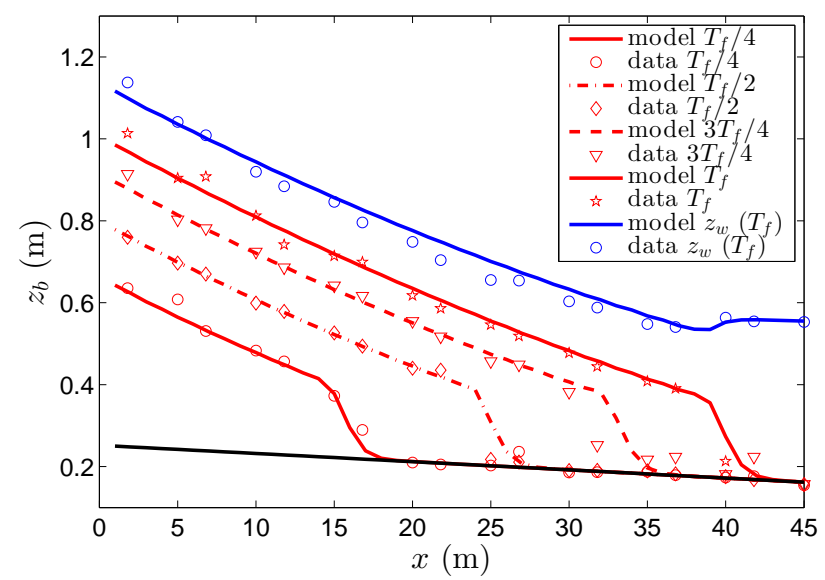

Figure 7 Experimental and simulated bed elevation at different times and water elevation at the final time-step of run 1 of the Seal et al. (1997) experiments using $\Delta x=1 \mathrm{~m}, L_{a}=2 \mathrm{~m}, L_{d}=10 \mathrm{~m}$ and $L_{\sigma}=100 \mathrm{~m}$.

there is no clear discussion on their capability to capture supercritical flows as observed in run 1. The model used by Belleudy (2001) was not able to model run 1 and 2 in which supercritical flows were significant.

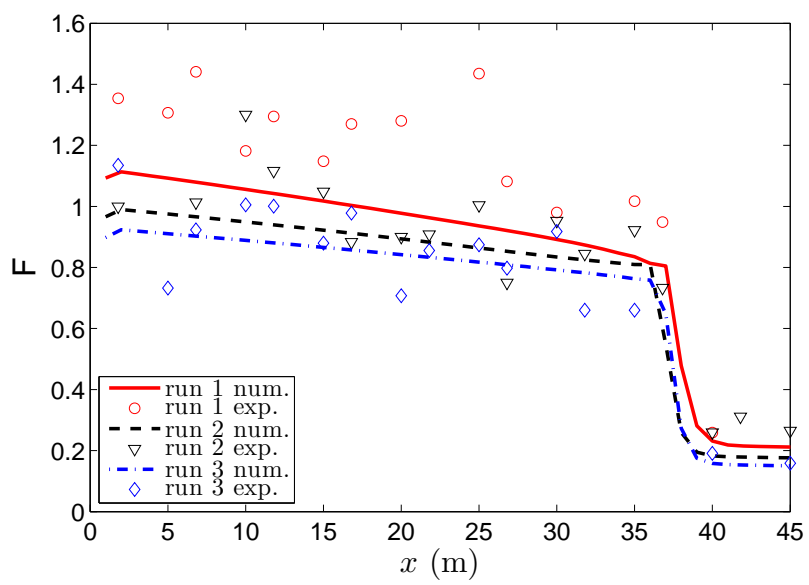

Figure 8 Experimental and simulated Froude number calculated at $t=T_{f}$ for the 3 runs $\left(\Delta x=1 \mathrm{~m}, L_{a}=2 \mathrm{~m}, L_{d}=10 \mathrm{~m}\right.$ and $L_{\sigma}=100 \mathrm{~m}$ ).

Figure 9 presents the experimental and simulated front velocity for the three runs. Again, the RubarBE code yields good results. The front velocity appears to be controlled by the sediment injection rate and by the height of the front. Indeed, assuming that the deposit can be described with a constant front height $\left(H_{F} \approx 0.15 \mathrm{~m}\right)$ and a slope $S$ constant over the deposit, the length of the deposit equals $L_{d}=\left(H_{d}-H_{F}\right) /\left(S-S_{0}\right)$ with $H_{d}$ the height of the deposit at the injection point, and the front velocity can be estimated with:

$$
C_{F}=\frac{1}{\left[H_{F}+\left(H_{d}-H_{F}\right) / 2\right](1-\phi)} \min \left(q_{s b}, q_{s, i n}\right)
$$

where $q_{s b}$ is the bedload transport per unit width over the deposit calculated using some transport capacity formula (in this specific case, we used the Meyer-Peter \& Müller, 1948, formula), and $q_{s, i n}=Q_{s, i n} /\left(\rho_{s} B\right)$ is the volume input of sediment per unit width. The Manning-Strickler equation is used to calculate the water depth and bed shear stress. If $q_{s b}<q_{s, i n}$, the excess volume of sediment is laid linearly over the deposit such as $\Delta z=0$ at the front (modification of the deposit slope). 
This simple analytical formulation yields an average front velocity in agreement with experimental data (cf. Figure 9). There is however a slight underestimation of the front velocity at the beginning of the experiments because of the choice of a constant front height. It clearly confirms that the front velocity is mainly governed by the sediment injection rate and by the front height.

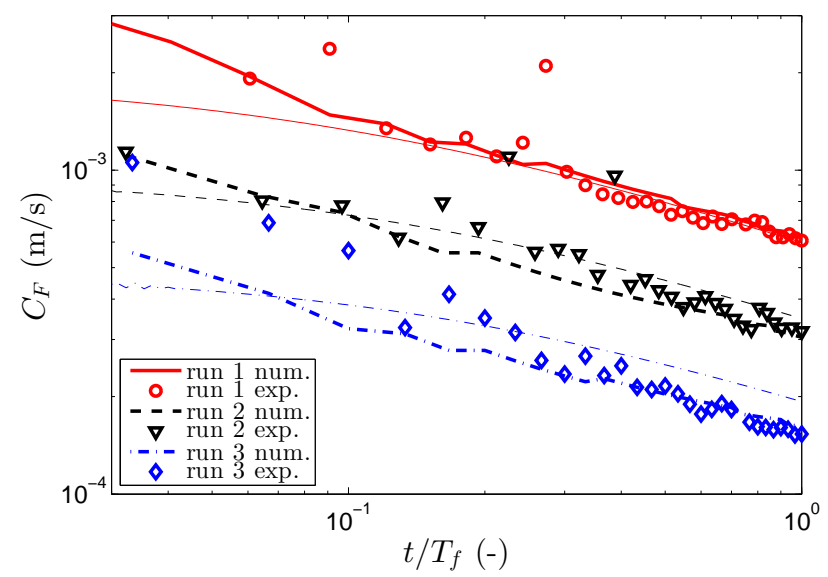

Figure 9 Experimental and simulated front velocity for the 3 runs $\left(\Delta x=1 \mathrm{~m}, L_{a}=2 \mathrm{~m} L_{d}=10 \mathrm{~m}\right.$ and $L_{\sigma}=100 \mathrm{~m}$, thin lines correspond to Eq. 11).

\subsection{Sensitivity of the model on the mesh size and adaptation length}

Figure 10a presents the temporal evolution of the front slope $S_{F}$ for the experimental results of Seal et al. (1997). One should yet be careful when studying the slope of the front based on experimental results. Indeed, results are sensitive to the position of the measurements, which are not regular and maybe too scarce. When $\Delta x=3.2 \mathrm{~m}$, the slope generally appears much smaller as the two points defining this slope do not necessarily correspond to the edges of the front slope. Even if a large scatter can be observed on Figure 10a, the front slope appears not to vary with time and $S_{F} \approx 0.1$.

Figure 10b presents some sensitivity analysis on the mesh size and adaptation length. These two parameters do not affect significantly the general trend of the results in terms of bed evolution. Their main impact is on the front slope, which decreases exponentially with larger values of $\Delta x$ or $L_{a}$. Indeed, larger values for both $\Delta x$ and $L_{a}$ lead to larger diffusion in the system. When $L_{a}>\Delta x$, results are less sensitive to the size of the mesh. It is difficult here to assess which values for $L_{a}$ are the more accurate to reproduce the experiment due to the lack of data and also because of the sensitivity of the front slope to the mesh size. However, $L_{a} \approx 1 \mathrm{~m}$ for loose meshes to $2 \mathrm{~m}$ for finer meshes appears to be the best trade-off to reproduce both the front and the overall deposit shape (Béraud et al., 2011). Eq. 8 yields $L_{a}$ values ranging from 1 to $3 \mathrm{~m}$ depending on the bed shear stress. Results obtained using Eq. 9 with $\alpha_{\text {Las }}=5$ or 10 are similar to those obtained with a constant value $\left(L_{a}=1\right.$ or $2 \mathrm{~m}$, respectively, see Figure 10) since it yields a value close to $1 \mathrm{~m}$ (respectively $2 \mathrm{~m}$ ) at the downstream part of the deposit. As discussed previously, the width of the river $B$ appears to be the best parameter to scale $L_{a}$ for a $1 \mathrm{D}$ model although there needs additional experiments to confirm it.

\subsection{Grain size evolution}

Sub-surface was sampled for different time-periods by Seal et al. (1997) using the Klingeman, Chaquette, and Hammond (1979) method. In the experiments, the sub-surface grain size appears to be finer than the surface grain size. This was explained by Toro-Escobar et al. (1997) as some vertical fining also occurred during the experiments due to infiltration. In Figure 11, the measured $d_{50}$ and 
(a)

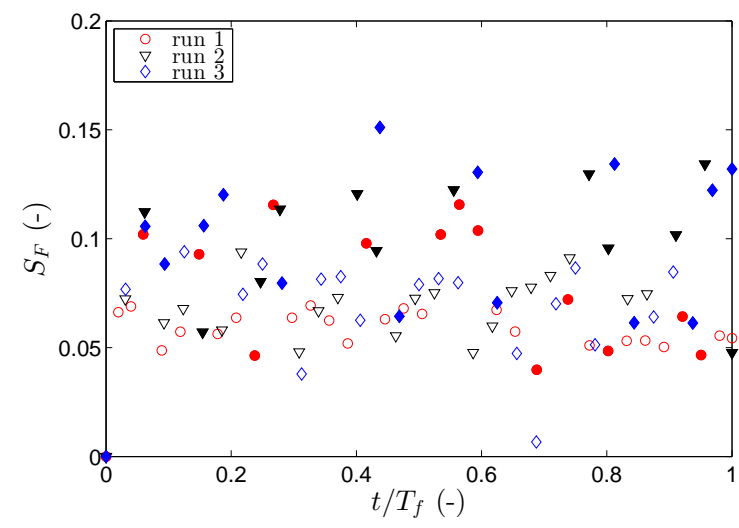

(b)

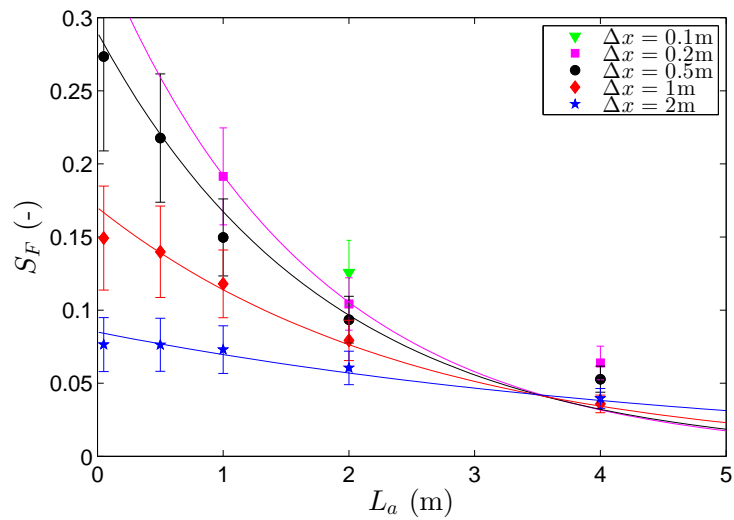

Figure 10 Evolution of the front slope $S_{F}$ of the Seal et al. (1997) experiments for the three runs (filled symbols are used when $\Delta x=1.8 \mathrm{~m}$, empty symbols when $\Delta x=3.2 \mathrm{~m}$ ) (a) and averaged front slope obtained thanks to the numerical model for the run 1 using different values for the mesh size and adaptation length (b) (error bars correspond to the fluctuation throughout time, thin lines correspond to curve fitting using an exponential function).

$\sigma$ in the sub-surface are plotted as a function of the downstream position made dimensionless with the front position $x_{F}$. Despite the significant scatter, one can observe a clear downstream fining resulting in a decrease of the median grain size from $d_{50} \approx 7.5 \mathrm{~mm}$ to $d_{50} \approx 4.5 \mathrm{~mm}$, and a decrease of the standard deviation from $\sigma \approx 6.5$ to $\sigma \approx 5.5$. One can observe also a larger scatter close to the front with, for some of the measurements, a sharper decrease in the median grain size. Such behaviour in $d_{50}$ and $\sigma$ was also observed from the modelling by Cui et al. (1996); Langendoen and Alonso (2008) and typically corresponds to the selective transport with the finest fraction transported easier downstream.
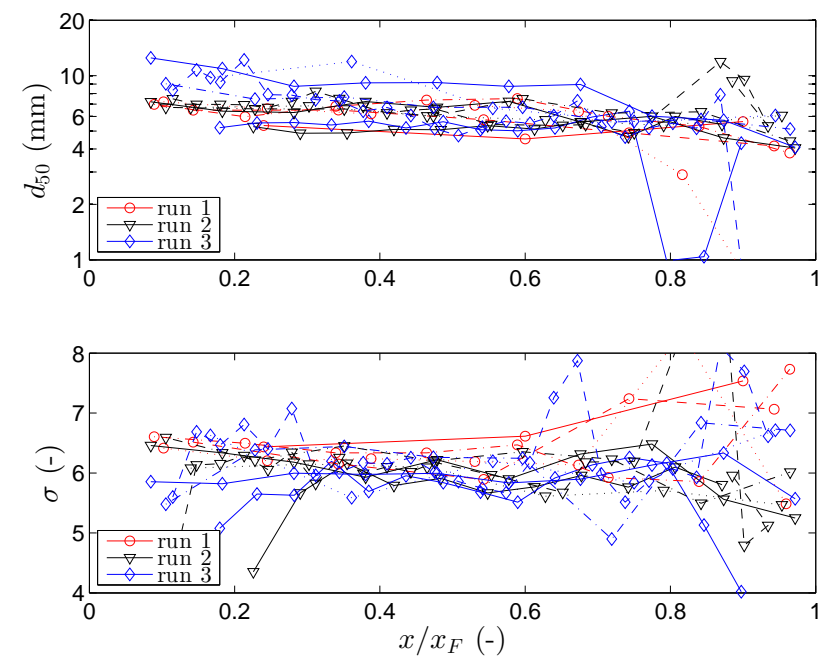

Figure 11 Evolution of the grain size characteristics of the Seal et al. (1997) experiments for the three runs as a function of the downstream position made dimensionless with the front position $x_{F}$.

In Figure 12, the experimental and simulated grain size characteristics are plotted as a function of the position along the deposit for the run 1. It is important here to distinguish the active layer (Figure 12a), corresponding to the surface, and the bed layer (Figure 12b), corresponding to the sub-layers. The active layer characteristics are consistent with measurements with a relatively low decrease of the grain size upstream and a sharper decrease close to the front. The bed layer characteristics appear more sensitive to $L_{d}$ and $L_{\sigma}$. Median grain size $\left(d_{50}\right)$ decreases rapidly in the first $10 \mathrm{~m}$ before reaching an asymptote (Cui et al., 1996), which is sensitive to $L_{d}$. This 
effect is emphasized since a single layer is used for the modelling. Apart for the front, the active layer presents coarser sediments than the injection (fine sediments being transported downstream) whereas the bed layer is finer (sediment from the active layer mixed with finer sediments deposited previously). The use of small $L_{d}$ and $L_{\sigma}$ values $\left(L_{d}=5 \mathrm{~m}\right.$ or $\left.L_{\sigma}=20 \mathrm{~m}\right)$ yields a too strong decrease of $d_{50}$ and $\sigma$, respectively. Also, $L_{d} \approx L_{\sigma}$ tends to affect results for $\sigma$ leading to a sharper decrease. The model is not as sensitive to $L_{\sigma}$ as to $L_{d}$.

(a)
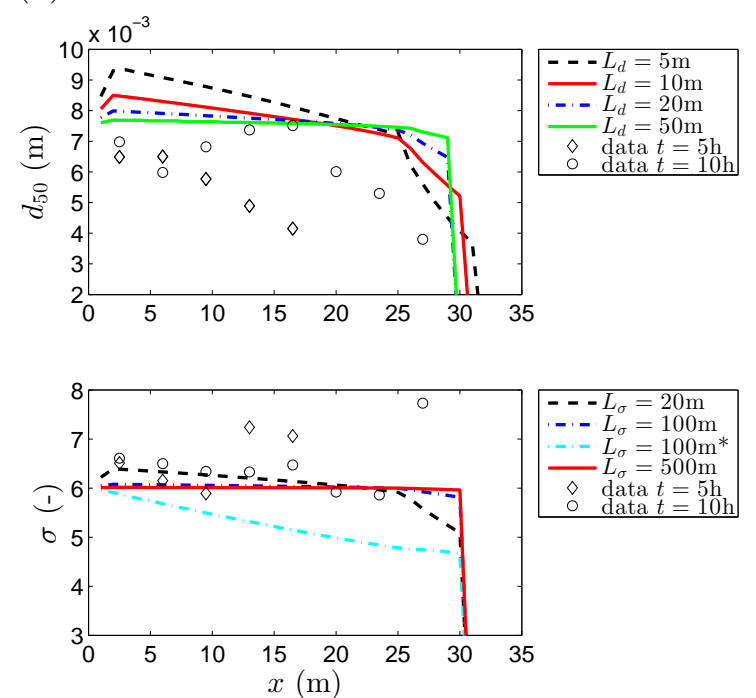

(b)
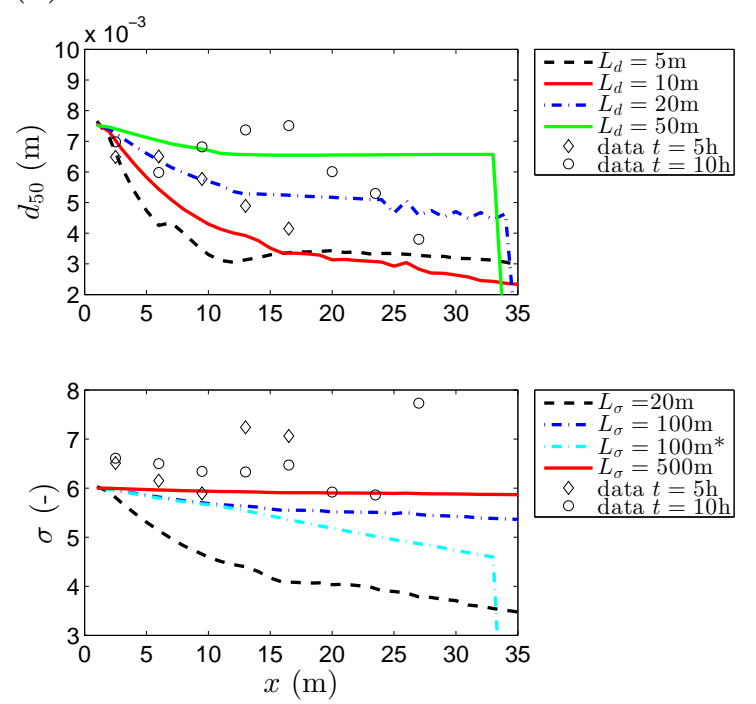

Figure 12 Experimental $d_{50}$ and $\sigma$ values along the deposit of Seal et al. (1997) experiments for the run 1 at $t=5$-6.5 $\mathrm{h}$ and $t=6.5-10 \mathrm{~h}$ together with the numerical results for the active layer (a) and bed layer (b) at $t=10 \mathrm{~h}$ (The sensitivity analysis on $L_{d}$ is made with $L_{\sigma}=100 \mathrm{~m}$ whereas the sensitivity analysis on $L_{\sigma}$ is made with $L_{d}=10 \mathrm{~m}$ except for $*$ for which $L_{d}=100 \mathrm{~m}$ ).

As discussed previously, $L_{d}$ and $L_{\sigma}$ were first scaled with the length of the equilibrium reach $L \approx 45 \mathrm{~m}$ (length of the flume). $L_{d}=20 \mathrm{~m}$ was chosen here since $L_{d}=45 \mathrm{~m}$ would have yielded a less pronounced downstream fining than measured as shown on Figure 12. On the contrary, for the sorting coefficient, a larger value was used $\left(L_{\sigma}=100 \mathrm{~m}\right)$ since nearly no longitudinal evolution was observed in the experiments. The use of too small values for $L_{d}$ and $L_{\sigma}$ would yield unrealistic results with too strong downstream fining and sorting. Although a single bed layer was assumed for these simulations, our results appear to be more accurate than those of Qian et al. (2015) and as good as those from Langendoen and Alonso (2008). The proposed model is robust and very parsimonious since only two parameters are needed to describe a sediment mixture $\left(d_{50}\right.$ and $\left.\sigma\right)$ and only two coefficients are needed to be calibrated $\left(L_{d}\right.$ and $\left.L_{\sigma}\right)$ and they can be scaled using the length of the reach in equilibrium. As a comparison, simulating downstream fining using a multi-class model may be difficult to calibrate since results are sensitive to several parameters that are still not perfectly understood and function of the grain size (critical bed shear stress, hiding and exposure functions, adaptation length).

\section{Conclusion}

A 1D numerical code (RubarBE) using an original simple grain size representation for minimizing the number of calibration constants was used to simulate the test case of bed aggradation by Seal et al. (1997). A discussion on the experimental test case (porosity, front velocity) is provided together with the validation of the RubarBE code. Good agreement was found between simulated and experimental results on morphological evolution. Trends of grain size downstream fining are 
also properly reproduced by the model. RubarBE was shown to be a robust and parsimonious code, well suited for natural cases where the description of the bed is generally limited, and complex flows (supercritical, interaction with structures, etc.) can occur. It successively reproduced bed evolution for natural test cases in case of short-term (event) or mid-term (several months or years) modelling (El kadi Abderrezzak et al., 2008; El kadi Abderrezzak \& Paquier, 2009; Camenen et al., 2015). The present paper discussed more specifically three parameters that are inherent to this model to simulate bed and sediment characteristic evolutions: the non-equilibrium adaptation length $L_{a}$ and the grain-size related adaptation lengths $L_{d}$ and $L_{\sigma}$.

- The adaptation length for sediment transport $L_{a}$ appears to be in the order of one metre for the Seal et al. (1997) experiments. It affects mainly the slope of the front in a similar way as the mesh size since it adds some diffusion in the model. As pointed out by Wu and Wang (2008), for a 1D model, it should be larger than the mesh size and can typically be scaled by the width of the river for river modelling.

- The sediment size and sorting adaptation lengths $L_{d}$ and $L_{\sigma}$ are one or two orders of magnitude larger than $L_{a}$ and $L_{\sigma}>L_{d}$. Both adaptation lengths should be scaled by the equilibrium reach length $L$.

One limit of the model is the discrete representation of the bed layers (Blom, 2008). Proper criteria are needed to fix or adapt sub-layer thickness in order to better describe the possible vertical evolution of the bed characteristics in case of aggrading beds and improve the present results. Such criteria should be function of both the active and sub-layer characteristics. The estimation of the critical bed shear stress may also be an issue when using excess-bed shear stress formulas such as the Meyer-Peter and Müller (1948) formula since partial transport may occur. A first improvement would be to use a formula that allows a weak sediment transport for very low bed shear stress (Camenen \& Larson, 2005; Recking, 2013). An additional routine would be necessary to modify grain size characteristics of the sediments transported in this specific case. It should be noted that results are also sensitive to the porosity, which is an important factor but difficult to estimate in the case of a sediment mixture (Wu \& Wang, 2007). In order to reproduce the process of vertical sorting reported by Seal et al. (1997) and quantified by Toro-Escobar et al. (1997) with an empirical function, a new transfer function could be added to RubarBE code in order to mix a sediment deposit with the upper bed layer or create a new bed layer depending on the grain size characteristics of both masses of sediments. A more physical thickness of the active layer $\left(\delta_{A L} \approx 2 D_{90}\right)$ could also be used (van Niekerk et al., 1992). Such a function could also be useful to reproduce bed armouring and sediment infiltration in an armoured bed (Béraud, 2012) but also needs an adaptive porosity calculation for each layers.

Experiments by Seal et al. (1997) are of great interest for calibrating morphodynamic models. It appears however that uncertainties in the estimation of the grain size characteristics remain too large and local variations that are not fully understood remain present. Additional experimental data presenting detailed measurements of a grain fining would be of great interest for a full validation of morphodynamic models.

\section{Aknowledgements}

This study was supported by Irstea, the Feder-Interreg IV project: "Redynamization of the RestRhine" as well as the Rhône-Alpes region through the CMIRA ExploraPro financial support. We would like to thank Prof. Nikora, Prof. Uchida as well as the two other anonymous reviewers for their significant input to improve the quality of this paper. 


\section{References}

Armanini, A., \& di Silvio, G. (1986). Discussion of "A depth-integrated model for suspended sediment transport" by G. Galappatti and C. B. Vreugdenhil. Journal of Hydraulic Research, $24(5), 437-442$.

Armanini, A., \& di Silvio, G. (1988). A one-dimensional model for the transport of a sediment mixture in non-equilibrium conditions. Journal of Hydraulic Research, 26 (3), 275-292.

Ashida, K., \& Michiue, M. (1971). An investigation of river bed degradation downstream of a dam. In Proc. 14th IAHR Congress (p. 1-9). Paris, France.

Balayn, P. (2001). Contribution à la modélisation numérique de l'évolution morphologique des cours d'eau aménagés lors de crues [A contribution to numerical modelling of bed evolution of channelized stream during floods]. (Unpublished doctoral dissertation). Claude Bernard University, Lyon 1, Lyon, France. (138p., in French)

Bell, R. G., \& Sutherland, A. J. (1983). Nonequilibrium bed-load transport by steady flow. Journal of Hydraulic Engineering, 109(3), 351-367.

Belleudy, P. (2000). Numerical simulation of sediment mixture deposition, part 1: analysis of a flume experiment. Journal of Hydraulic Research, 38(6), 417-426.

Belleudy, P. (2001). Numerical simulation of sediment mixture deposition, part 2: a sensitivity analysis. Journal of Hydraulic Research, 39(1), 25-31.

Béraud, C. (2012). Modélisation numérique des impacts de recharges sédimentaires en rivière aménagée. Cas du Vieux-Rhin entre Kembs et Breisach [Numerical modelling of the sediment feeding impacts in engineered rivers. The case of the Old Rhine, between Kembs and Brisach] (Unpublished doctoral dissertation). C. Bernard University, Lyon 1, Lyon, France. (252 p., in French)

Béraud, C., Le Coz, J., Camenen, B., \& Paquier, A. (2011). 1D numerical simulation of sediment downstream fining during bed aggradation using a simplified grain size description. In Proc. 7th IAHR symposium on River, Coastal and Estuarine Morphodynamics (p. 1-10). Beijing, China. (CD Rom)

Blom, A. (2008). Different approaches to handling vertical and streamwise sorting in modeling river morphodynamics. Water Resources Research, 44(W03415), 1-16.

Camenen, B., Grabowski, R., Latapie, A., Paquier, A., Solari, L., \& Rodrigues, S. (2015). On the estimation of the bed-material transport and budget along a river segment: application to the Middle Loire River, France. Aquatic Sciences, 78, 71-81.

Camenen, B., Holubová, K., Lukač, M., Le Coz, J., \& Paquier, A. (2011). Assessment of methods used in 1D models for computing bedload transport in a large river: the Danube River in Slovakia. Journal of Hydraulic Engineering, 137(10), 1190-1199.

Camenen, B., \& Larson, M. (2005). A bedload sediment transport formula for the nearshore. Estuarine, Coastal \&5 Shelf Science, 63, 249-260.

Colombini, M., Seminara, G., \& Tubino, M. (1987). Finite-amplitude alternate bars. Journal of Fluid Mechanics, 181, 213-232.

Cui, Y., \& Parker, G. (1998). The arrested gravel front: stable gravel-sand transitions in rivers; Part 2: General numerical solution. Journal of Hydraulic Research, 36(2), 159-182.

Cui, Y., Parker, G., \& Paola, C. (1996). Numerical simulation of aggradation and downstream fining. Journal of Hydraulic Research, 34(2), 185-204.

Daubert, A., \& Lebreton, J. C. (1967). Etude expérimentale et sur modèle mathématique de quelques aspects des processus d'érosion des lits alluvionnaires, en régime permanent et nonpermanent [Study with a mathematic model on some erosion processes in alluvial rivers for steady and unsteady regimes]. In Proc. 12th IAHR Congress (Vol. 3, p. 26-37). Fort Collins, Colorado, USA. (in French)

Deigaard, R. (1980). Longitudinal and transverse sorting of grain sizes in alluvial rivers (series paper No. 26). Denmark: Institute for Hydrodynamic and Hydraulic Engineering, Technical 
Univiversity of Denmark.

di Silvio, G. (1992). Modelling sediment transport under different hydrological and morphological circumstances. In P. Billi, R. D. Hey, C. R. Thorne, \& P. Tacconi (Eds.), Gravel bed river III: Dynamics of gravel-bed rivers (p. 363-372). John Wiley and Sons Ltd. (Chapter 18)

Egiazaroff, I. V. (1955). Calculation of nonuniform sediment concentrations. Journal of Hydraulic Division, 91 (HY4), 225-253.

El kadi Abderrezzak, K., \& Paquier, A. (2009). One-dimensional numerical modeling of sediment transport and bed deformation in open channels. Water Resources Research, 45(W05404), $1-20$.

El kadi Abderrezzak, K., \& Paquier, A. (2011). Applicability of sediment transport capacity formulas to dam-break flows over movable beds. Journal of Hydraulic Engineering, 137(2), 209-221.

El kadi Abderrezzak, K., Paquier, A., \& Gay, B. (2008). One-dimensional numerical modelling of dam-break waves over movable beds: application to experimental and field cases. Environmental Fluid Mechanics, 8(2), 169-198.

Ferguson, R. I., Church, M., \& Weatherly, H. (2001). Fluvial aggradation in vedder river: Testing a one-dimensional sedimentation model. Water Resources Research, 37(12), 3331-3347.

Ferguson, R. I., \& Wathen, S. (1998). Tracer-pebble movement along a concave river profile : Virtual velocity in relation to grain size and shear stress. Water Resources Research, 34(8), 2031-2038.

Gomez, B., Rosser, B. J., Peacock, D. H., Murray Hicks, D., \& Palmer, J. A. (2001). Downstream fining in a rapidly aggrading gravel bed river. Water Resources Research, 37(6), 1813-1823,.

Hirano, M. (1971). River bed degradation with armouring. Transaction of the Japanese Society of Civil Engineering, 3(2), 55-65. (in Japanese)

Hoey, T. B., \& Ferguson, R. (1994). Numerical simulation of downstream fining by selective transport in gravel bed rivers : model development and illustration. Water Resources Research, 30(7), 2251-2260.

Klingeman, P. C., Chaquette, C. J., \& Hammond, S. B. (1979). Bed material characteristics near Oak Creek sediment research facilities (Tech. Rep.). Corvallis, Oregon, USA: Water Resources Research Institute, Oregon State University.

Langendoen, E. J., \& Alonso, C. V. (2008). Modeling the evolution of incised streams: I. Model formulation and validation of flow and streambed evolution components. Journal of Hydraulic Engineering, 134(6), 749-762.

Meyer-Peter, E., \& Müller, R. (1948). Formulas for bed-load transport. In Proc. 2nd IAHR Congress (p. 39-64). Stockholm, Sweden.

Mikos̃, M. (1993). Fluvial abrasion of gravel sediments (Tech. Rep. No. 123). Zürich, Switzerland: Miteilungen der Versuchsanstalt für Wasserbau, Hydrologie und Glaziologie der ETH Zürich. (322p.)

Morris, P. H., \& Williams, D. J. (1999). A worldwide correlation for exponential bed particle size variation in subaerial aqueous flows. Earth Surface Processes 83 Landforms, 24, 835-847.

Paola, C., \& Seal, R. (1995). Grain size patchiness as a cause of selective deposition and downstream fining. Water Resources Research, 31(5), 1395-1407.

Paquier, A., \& El Kadi Abderrezzak, K. (2008). A model for bedload transport and morphological evolution in rivers : description and pertinence. In S. Benzoni Gavage \& D. Serre (Eds.), Hyperbolic problems: Theory, numerics, applications. (p. 285-296). Springer.

Parker, G. (1990). Surface-based bedload transport relation for gravel rivers. Journal of Hydraulic Research, 28(4), 417-436.

Parker, G. (1991). Selective sorting and abrasion of river gravel. I: Theory. Journal of Hydraulic Engineering, 117(2), 131-147.

Parker, G., \& Cui, Y. (1998). The arrested gravel front: stable gravel-sand transitions in rivers; Part 2: Simplified analytical solution. Journal of Hydraulic Research, 36(1), 75-100. 
Phillips, B. C., \& Sutherland, A. J. (1989). Spatial lag effects in bed load sediment transport. Journal of Hydraulic Research, 27(1), 115-133.

Qian, H., Cao, Z., Pender, G., Liu, H., \& Hu, P. (2015). Well-balanced numerical modelling of nonuniform sediment transport in alluvial rivers. International Journal on Sediment Research, 30, 117-130.

Rahuel, J. L., Holly, F. M., Chollet, J. P., Belleudy, P. J., \& Yang, G. (1989). Modeling of riverbed evolution for bedload sediment mixtures. Journal of Hydraulic Engineering, 115(11), $1521-1542$.

Recking, A. (2013). A simple method for calculating reach-averaged bedload transport. Journal of Hydraulic Engineering, 139(1), 70-75.

Seal, R., Paola, C., Parker, G., Southard, J. B., \& Wilcock, P. R. (1997). Experiments on downstream fining of gravels: I. Narrow-channel runs. Journal of Hydraulic Engineering, 123(10), 874-884.

Seal, R., Parker, G., \& Mullenbach, C. P. B. (1995). Laboratory experiments on downstream fining og gravel, narrow channel runs 1 through 3: supplemental methods and data. (External Memorandum No. 239). University of Minnesota, USA: St Anthony Falls Laboratory.

Stecca, G., Siviglia, A., \& Blom, A. (2014). Mathematical analysis of the saint-venant-hirano model for mixed-sediment morphodynamics. Water Resources Research, 50, 7563-7589.

Sternberg, H. (1875). Untersuchungen über längen- und querprofil geschiebeführender flüsse [Study on the longitudinal and transversal bed-load transport in rivers]. Zeitschrift Bauwesen, 25, 483-506. (in German)

Strickler, A. (1923). Beiträge zur frage der geschwindigkeitsformel und der rauhigkeitszahlen für ströme, kanäle und geschlossene leitungen [Contributions to the questions of velocity formulations and roughness values for rivers, canals, and closed ducts] (Mitteilung No. 16). Bern, Switzerland: Amt für Wasserwirtschaft. (in German)

Surian, N. (2002). Downstream variation in grain size along an alpine river: analysis of controls and processes. Geomorphology, 43, 137-149.

Toro-Escobar, C. M., Parker, G., \& Paola, C. (1997). Transfer function for the deposition of poorly sorted gravel in response to streambed aggradation. Journal of Hydraulic Research, 35 (4), 563-566.

Toro-Escobar, C. M., Parker, G., \& Paola, C. (2000). Experiments on downstream fining of gravel. ii wide and sandy runs. Journal of Hydraulic Engineering, 126(3), 198-208.

van Niekerk, A., Vogel, K. R., Slingerland, R. L., \& Bridge, J. S. (1992). Routing of heterogeneous sediments over movable bed : Model development. Journal of Hydraulic Engineering, 118(2), $246-262$.

Viparelli, E., Sequeiros, O. E., Cantelli, A., Wilcock, P. R., \& Parker, G. (2010). River morphodynamics with creation/consumption of grain size stratexperiments, 2: numerical model. Journal of Hydraulic Research, 48(6), 727-741.

Vogel, K. R., van Niekerk, A., Slingerland, R. L., \& Bridge, J. S. (1992). Routing of heterogeneous sediments over movable bed : Model verification. Journal of Hydraulic Engineering, 118(2), 263-279.

Wilcock, P. R., \& Crowe, J. C. (2003). Surface-based transport model for mixed-size sediment. Journal of Hydraulic Engineering, 129(2), 120-128.

Wright, S., \& Parker, G. (2005). Modeling downstream fining in sand-bed rivers. II: Application. Journal of Hydraulic Research, 43(6), 621-631.

Wu, W., Viera, D. A., \& Wang, S. S. Y. (2004). One-dimensional numerical model for nonuniform sediment transport under unsteady flows in channel networks. Journal of Hydraulic Engineering, 130(9), 914-923.

Wu, W., \& Wang, S. S. Y. (2007). One-dimensional modeling of dam-break flow over movable beds. Journal of Hydraulic Engineering, 133(1), 48-58. 
Wu, W., \& Wang, S. S. Y. (2008). One-dimensional explicit finite-volume model for sediment transport. Journal of Hydraulic Research, 46(1), 87-98.

Wu, W., Wang, S. S. Y., \& Jia, Y. F. (2000). Nonuniform sediment transport in alluvial rivers. Journal of Hydraulic Research, 38(6), 427-434.

Yu, A.-B., Standish, N., \& McLean, A. (1993). Porosity calculation of binary mixtures of nonspherical particles. Journal of the American Ceramic Society, 76(11), 2813-2816.

\section{Notation}

Latin and Greek variables

$A b=$ cross-sectional area of the bed above a reference datum

$B=$ width of the river

$c_{f} \quad=$ volume concentration of fine sediments

$C_{F}=$ time-averaged front velocity

$d_{50}=$ median diameter

$d_{x} \quad=$ grain diameter at which $x$ percent of the distribution in mass lies below

$\mathrm{F} \quad=$ Froude number

$h=$ water depth

$H_{d} \quad=$ height of the deposit at the injection point

$H_{F} \quad=$ front height

$H_{\text {tail }}=$ height of the tailgate

$L=$ length of the reach in morphological equilibrium

$L_{a}=$ non-equilibrium adaptation length

$L_{d} \quad=$ adaptation length related to the median diameter evolution

$L_{\sigma} \quad=$ adaptation length related to the sorting coefficient evolution

$M \quad=$ sediment mass

$q_{s b}=$ volumetric bedload transport per unit width

$Q_{0} \quad=$ water discharge

$Q_{s} \quad=$ volumetric sediment transport

$Q_{s *} \quad=$ equilibrium sediment transport or sediment transport capacity

$Q_{s 0} \quad=$ sediment input

$t \quad=$ time

$T_{f} \quad=$ final time of the runs

$u_{*} \quad=$ shear velocity

$U=$ depth-averaged velocity of the flow

$r_{d}=$ ratio between fine and coarse sediment diameters

$S_{b} \quad=$ slope of the bed

$V \quad=$ volume of the deposit

$W_{s} \quad=$ settling velocity

$x \quad=$ longitudinal direction

$x_{0} \quad=$ position of the sediment input

$x_{F} \quad=$ position of the front

$z_{w, \text { tail }}=$ water level at the tailgate

$\alpha_{d} \quad=$ constant for Sternberg equation for $d$

$\alpha_{\sigma}=$ constant for Sternberg equation for $\sigma$

$\alpha_{L}=$ constant for adaptation length equations

$\delta_{A L}=$ active layer thickness

$\phi \quad=$ porosity

$\rho_{s} \quad=$ sediment density

$\sigma \quad=$ sorting coefficient 
Author-produced version of the article published in Journal of hydraulic research, 2018; 56 (2) : 168-180

The original publication is available at https://www.tandfonline.com/doi/full/10.1080/00221686.2017.1312575

doi : 10.1080/00221686.2017.1312575

$\theta=$ Shields parameter

$\theta_{c r}=$ critical Shields parameter for the inception of movement

Subscripts and exponents

$d n=$ upstream cell

up $\quad=$ downstream cell

dep $=$ deposit

ero $=$ erosion

tra $=$ transit

$f \quad=$ fine

$c \quad=$ coarse

adj $\quad=$ adjusted

$F \quad=$ front 